\title{
Genetic diversity in Banksia and Dryandra (Proteaceae) with emphasis on Banksia cuneata, a rare and endangered species
}

\author{
TINA L. MAGUIRE \& MARGARET SEDGLEY* \\ Department of Horticulture, Viticulture and Oenology, The University of Adelaide, Waite Campus, Plant Research \\ Centre, PMB 1, Glen Osmond, SA 5064, Australia
}

\begin{abstract}
Random amplified polymorphic DNA (RAPD) markers were investigated as a tool for estimating genetic diversity within 33 species of Banksia and three species of Dryandra. Three primers were used on DNA from 10 seeds per species, and band data were pooled to give between 52 and 89 bands per species, most of which were polymorphic. Genetic diversity was calculated using six published metrics on three species, for which allozyme data were also available. Based on between-method consistency, three metrics were chosen for analysis of the full data set. Levels of genetic diversity in Banksia and Dryandra ranged from 0.59 to 0.90 . Based on this information, a detailed study was conducted on all 10 known populations of $B$. cuneata, a rare and endangered species, with a restricted geographical distribution in south-western Australia. Estimates of genetic diversity ranged from 0.65 to 0.74 , which is high for a rare and endangered species. Analysis of molecular variance (AMOVA) was used to partition RAPD variation within and between populations. Nearly all of the variation was attributable to individuals within populations, indicating a lack of population divergence. It is suggested that the combination of bird pollination and high outcrossing rates in $B$. cuneata maintain genetic diversity and cohesion between the populations.
\end{abstract}

Keywords: Amova, Banksia, Dryandra, population genetics, Proteaceae, RAPDs.

\section{Introduction}

Scientific approaches to the conservation and exploitation of plant genetic resources require a detailed knowledge of the amount and distribution of genetic diversity within a species. Allozymes have been used in Banksia to estimate genetic diversity and high levels have been reported, amongst the highest recorded for plants (Scott, 1980; Schemske \& Lande, 1985; Carthew et al., 1988; Coates \& Sokolowski, 1992). More recently many workers have moved to DNA markers such as RAPDs, which have been useful for population genetic studies in a number of genera (Chalmers et al., 1992; Huff et al., 1993). It has also been suggested that RAPDs may be an appropriate technique to monitor diversity in plant populations (Anderson \& Fairbanks, 1990; Virk et al., 1995).

*Correspondence. E-mail: msedgley@waite.adelaide.edu.au
Banksia cuneata A. S. George is a rare and endangered species known only from 10 populations ( $\approx 550$ plants $)$ in the central area of south-western Australia in an area of $\approx 90 \mathrm{~km}^{2}$. It is found in deep yellow sands which occupy $10-15$ per cent of the area, giving it a fragmented distribution. Associated with these soils is a rich and diverse flora dominated by species of the families Proteaceae, Myrtaceae and Leguminosae. In the last 50-60 years land clearing for agriculture and other disturbances have reduced the $B$. cuneata population size to about 7 per cent of its original distribution, and it now occurs in remnants of native vegetation. The mating system and patterns of genetic variation for six populations of $B$. cuneata have been determined using allozyme electrophoresis (Coates \& Sokolowski, 1992), and estimates of outcrossing based on six loci ranged from $0.67-0.95$, with low levels of selfing. The populations were divided into two groups, with gene flow within groups but not between them. It was 
suggested that an ecological barrier to pollinator movement may be responsible for the restriction of between-group gene flow.

This study investigated levels of genetic diversity within species of Banksia and Dryandra using RAPDs, and evaluated six methods of data analysis. Based on this information, a detailed study determining patterns of genetic variation within and between all known populations of $B$. cuneata was conducted. Ten populations were included in this study, four of which had not been previously investigated.

\section{Materials and methods}

\section{Plant material}

Seeds of 33 species of Banksia and three species of Dryandra collected from natural populations were obtained from a commercial seed source (Nindethana Seed Service, WA). Seeds represent bulk collections from single or multiple sites of wild populations. The species chosen represented the two sister genera Banksia and Dryandra, and two subgenera, two sections and 13 series within the genus Banksia (George, 1981, 1988; Table 1). Ten seeds of each species were randomly selected for RAPD analysis.

Banksia cuneata seed material was collected from all 10 known populations (Fig. 1). Twenty seeds were randomly selected, one per plant, from each of four populations with in excess of 50 plants, and 10 seeds were collected, one per plant, from each of three populations with fewer than 50 plants. In three cases, the populations comprised fewer than 10 plants, so a one-seed sample was taken from each. In total 125 plants, $\approx 25$ per cent, of the remaining 550 plants were sampled.

\section{DNA isolation}

DNA was extracted from each seed using a modification of the method of Weining \& Langridge (1991) comprising: phenol/chloroform/isopropanol extraction for $5 \mathrm{~min}$ on ice, DNA precipitation for 1 min with ice-cold isopropanol and sodium acetate, with DNA recovered by centrifugation at $11600 \mathrm{~g}$ for $10 \mathrm{~min}$. The pellet was washed twice with 70 per cent ethanol, dried and dissolved in $50 \mu \mathrm{L}$ of $\mathrm{TE}$ buffer, with $1.0 \mu \mathrm{L}$ of RNAase (R40: $40 \mathrm{mg} / \mathrm{mL}$ RNAase $\mathrm{A}$ in TE), and stored at $4^{\circ} \mathrm{C}$ for up to 1 month.

DNA was subjected to gel electrophoresis on 1.6 per cent agarose gels in TBE buffer (Sambrook et al., 1989), and stained with ethidium bromide. DNA concentration was estimated by visual assessment of band intensities, compared to salmon sperm genomic DNA standards.

\section{DNA amplification and documentation}

DNA amplification was performed in a MJ Research Thermal Cycler. The programme commenced with a denaturation step at $94^{\circ} \mathrm{C}$ for $5 \mathrm{~min}$, followed by 40 cycles of $94^{\circ} \mathrm{C}$ for $1 \mathrm{~min}, 36^{\circ} \mathrm{C}$ for $1 \mathrm{~min}, 72^{\circ} \mathrm{C}$ for $2 \mathrm{~min}$, and terminated with an extension step at $72^{\circ} \mathrm{C}$ for $5 \mathrm{~min}$. Optimized reaction conditions were carried out in a $25 \mu \mathrm{L}$ total volume containing $1 \times$ Taq buffer (Gibco-BRL), $3 \mathrm{mM} \mathrm{MgCl}_{2}, 200 \mu \mathrm{M}$ each of dNTP (dGTP, dATP, dCTP, dTAP), 1 unit of Taq polymerase (Gibco-BRL), $0.5 \mu \mathrm{L}$ T4 gene 32 protein (Boehringher Mannheim), $1 \mu \mathrm{M} 10$ mer primer (Operon Technologies) and $10 \mathrm{ng}$ template DNA. Each reaction mix was overlaid with PCR grade paraffin oil. DNA amplification fragments were separated by 2 per cent agarose gel (Seakem, Promega) electrophoresis using TBE buffer (Sambrook et al., 1989). A negative control was added in each run to test for contamination. In order to test reproducibility, the selected primers were tested three times on the same sample, for a random subset of three DNA samples. To aid interpretation of band identity between gels, each contained a standard DNA sample and pGEM DNA marker. Gels were stained with ethidium bromide and fragment patterns were photographed under UV light with Polaroid 667 film. Polaroid photographs were scanned using a transmission scanner (Hewlett Packard Scanjet IIcx/T). The intensity and molecular weight of each visible band was determined using the software CREAM (Kem-En-Tec Software Systems, Blue Sky Scientific). Based on the faintest visible band of the molecular weight marker (pGEM) a minimum intensity threshold was established. Bands with an intensity greater than the minimum threshold were scored as present.

Sixty primers were evaluated for their suitability in a pilot survey (series OPA, OPB and OPC, Operon Technologies). Three primers were selected for the initial study of genetic diversity in 33 species of Banksia and three species of Dryandra. The primers OPA-20 (GTTGCGATCC), OPB-03 (CATCCCCTG) and OPB-04 (GGACTGGAGT) gave reproducible and informative markers. Five primers were selected for the detailed study on $B$. cuneata, OPA-1, OPA-4, OPA-9, OPA-11 and OPA-16 (Table 3). Band fragments included in the final analysis ranged between $2.5 \mathrm{~kb}$ and $100 \mathrm{bp}$ in length (Fig. 2), were scored as present (1) or absent (0) for 
Table 1 Band data and estimates of diversity for 33 species of Banksia and three of Dryandra using RAPDs. Taxonomy follows George $(1981,1988)$

Number of bands

Polymorphic Monomorphic Tota
Diversity (standard deviation)

Species

\section{Genus Banksia}

Subgenus Banksia

Section Banksia

Series Salicinae

Series Bauerinae
$B$. integrifolia*

B. robur

Series Grandes

$B$. grandis

B. solandri**

Series Quercinae

B. quercifolia**

B. baueri

Series Banksia

B. baxteri

B. candolleana

B. menziesii

B. serrata

Series Crocinae

B. burdettii ${ }^{* * *}$

B. prionotes

Series Cyrtostylis

B. ashbyi

B. attenuata

B. audax

B. elderiana

B. laevigata*

B. lindelyana*

B. praemorsa**

Series Prostratae

B. blechnifolia**

B. repens

82

61

63

52

51

86

84

60

79

53

89

57

69

60

69

52

58

69

57

55

77

57

82

B. caleyi

B. lemanniana

Series Coccineae

B. coccinea

Section Oncostylis

Series Spicigerae

$B$. ericifolia

B. occidentalis**

B. tricuspis**†

Series Dryandroideae $B$. dryandroides**

Series Abietinae

B. meisneri**** ${ }^{*}$

B. pulchella

66

59

66

$\begin{array}{ll}0 & 82 \\ 0 & \\ 0 & \\ 2 & \\ 1 & 5 \\ 2 & \\ 0 & \\ 0 & \\ 5 & \\ 1 & 54\end{array}$

82

61

$0.77(0.07)$

$0.79(0.06)$

$0.77(0.07)$

$0.72(0.06)$

$0.68(0.07)$

$54 \quad 0.67(0.07)$

$0.62(0.09)$

$0.73(0.06)$

$0.69(0.07)$

$0.72(0.06)$

$0.68(0.08)$

$0.67(0.07)$

$0.71(0.06)$

$0.74(0.06)$

$0.65(0.06)$

$0.71(0.08)$

$0.59(0.07)$

$0.70(0.08)$

$0.67(0.07)$

$0.69(0.09)$

$0.71(0.08)$

$0.61(0.09)$

$0.74(0.08)$

$0.77(0.07)$

$0.69(0.09)$

$0.72(0.09)$

$0.69(0.06)$

$0.59(0.13)$

$0.65(0.08)$

$0.69(0.09)$

$0.70(0.07)$

$0.79(0.08)$

$0.74(0.06)$

$0.81(0.07)$

$0.76(0.07)$

$0.78(0.06)$

Russell \& Rao (1940)
$0.86(0.04)$
$0.88(0.04)$

$0.82(0.03)$
$0.75(0.05)$

$0.83(0.04)$
$0.81(0.05)$
$0.82(0.03)$
$0.83(0.04)$
$0.77(0.04)$
$0.84(0.04)$

$0.83(0.04)$
$0.82(0.06)$
$0.77(0.04)$
$0.86(0.05)$
$0.88(0.04)$
$0.83(0.06)$
$0.85(0.05)$
$0.82(0.03)$
$0.79(0.05)$
$0.80(0.04)$
$0.83(0.04)$
$0.82(0.04)$
$0.90(0.04)$
$0.85(0.04)$
$0.74(0.09)$

$0.76(0.06)$

$0.73(0.07)$

$0.65(0.09)$

$0.85(0.05)$

77

$0.69(0.08)$

$0.78(0.09)$

$0.81(0.04)$

$0.89(0.05)$

66

$0.74(0.07)$

$0.70(0.09)$

$0.83(0.04)$

59

$0.73(0.06)$

$0.69(0.08)$

$0.83(0.05)$

67

$0.71(0.07)$

$0.67(0.09)$

$0.80(0.07)$ 
Table 1 Continued

Number of bands

Diversity (standard deviation)

Species $\quad$ Polymorphic Monomorphic Total Nei \& Li (1979) Jaccard (1901) Russell \& Rao (1940)

Subgenus Isostylis

$\begin{array}{lllllll}\text { B. } \text { illicifolia } & 60 & 1 & 61 & 0.71(0.08) & 0.67(0.09) & 0.80(0.05) \\ \text { B. oligantha* } & 48 & 0 & 48 & 0.73(0.07) & 0.69(0.09) & 0.85(0.04) \\ \text { B. } \text { cuneata }^{* *+} & 78 & 0 & 78 & 0.80(0.09) & 0.78(0.10) & 0.90(0.04)\end{array}$

Genus Dryandra
D. formosa
D. polycephela
55
76
D. carlinoides
59

$\begin{array}{llll}4 & 59 & 0.64(0.09) & 0.59(0.11) \\ 1 & 77 & 0.77(0.09) & 0.74(0.11) \\ 3 & 62 & 0.66(0.08) & 0.61(0.10)\end{array}$
$0.59(0.11)$
$0.75(0.05)$
$0.87(0.04)$
$0.76(0.05)$

Conservation status of Banksia and Dryandra species (George, 1987):

*species which are rare but not currently considered endangered or vulnerable;

**vulnerable species not presentiy endangered but at risk in the longer term;

***endangered species which may disappear from the wild within one or two decades if present land use and other causal factors continue;

$\dagger$ Declared rare flora under the Western Australian Wildlife Conservation Act 1950-79.

all individuals, and a matrix of RAPD phenotypes was assembled.

\section{Analysis of genetic diversity of Banksia and Dryandra}

Utilizing the matrix of RAPD phenotypes for each DNA sample, an index of genetic distance $(D)$ was calculated, $(D=1-F)$ where $F$ is similarity, using the following six methods: (1) $2 n_{11} /\left(2 n_{11}+n_{01}+n_{10}\right)$ from Nei \& Li (1979), where $n=$ number of band positions, $n_{11}=$ the number of positions where $x=1$ and $y=1, n_{00}=$ the number of positions where $x=0$ and $y=0, n_{01}=$ the number of positions where $x=0$

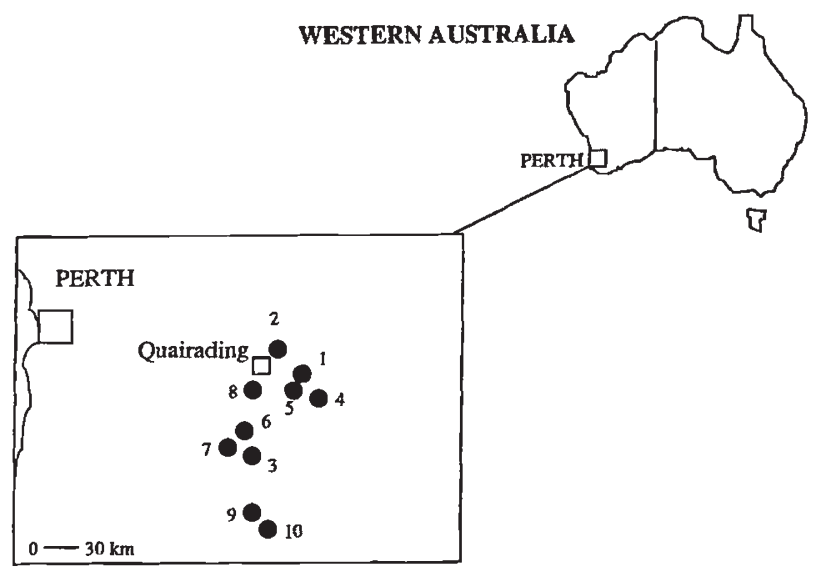

Fig. 1 Geographical range of Banksia cuneata in southwest Australia, showing locations of the 10 populations from which seed was collected. and $y=1, n_{10}=$ the number of positions where $x=1$ and $y=0 \quad(x$ and $y=$ individuals compared); (2) $n_{11} /\left(n-n_{00}\right)$ from Jaccard (1901); (3) $n_{11} / n$ from Russell \& Rao (1940); (4) $\left(n_{11}+n_{00}\right) / n$ from Apostol et al. (1993); (5) $n\left(1-\left(n_{11} / n\right)\right)$ from Excoffier et al. (1992); (6) $\left(n_{11}+n_{00}\right) /\left(n_{11}+2\left(n_{10}+n_{01}\right)+n_{00}\right)$ from Rodgers \& Tanimoto (1960).

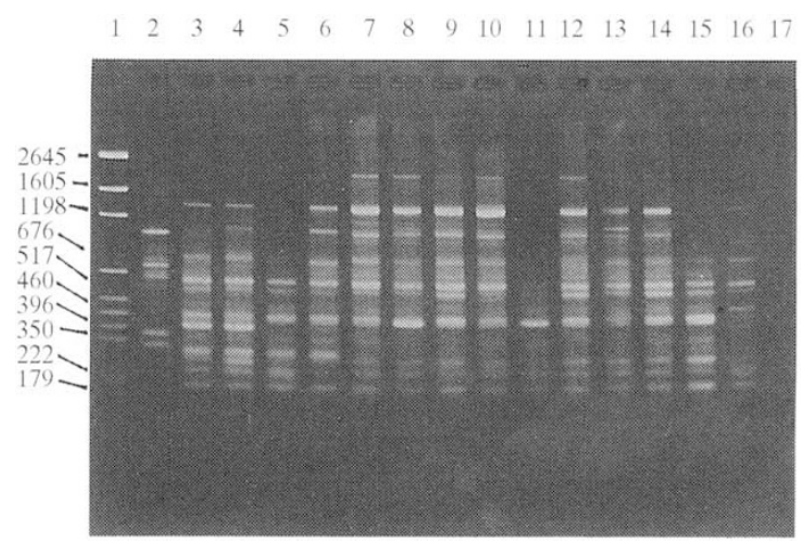

Fig. 2 Agarose gel showing RAPD markers produced using primer OPA-9 for individuals of Banksia cuneata . Lane 1 shows the DNA size standard pGEM (Promega), lane 2 shows the standard individual to aid in band identity for between-gel comparisons, lanes 3-6 show individuals in population 7, lanes 7-16 show individuals in population 3 and lane 17 is the negative control. Bands within the molecular size range $2.5 \mathrm{~kb}$ to $100 \mathrm{bp}$ are scored as present (1) or absent (0), and a matrix with elements of 1 or 0 is established for each individual, for all primers used in the study. The matrix is used in genetic distance and AMOVA analyses. 
Distance matrices were calculated using the statistical package RAPDISTANCE (Amstrong et al., 1994). The mean distance value for each species was taken as an estimate of genetic diversity, and the standard deviation of the mean was calculated for each data set.

\section{Analysis of genetic diversity of B. cuneata}

Based on the initial analysis of genetic diversity using six published metrics, the method of Nei \& $\mathrm{Li}$ (1979) and the statistical package RAPDISTANCE (Amstrong et al., 1994) were used for analysis of $B$. cuneata data. Analysis of molecular variance (AMOva; Excoffier et al., 1992) was used to estimate variance components attributable to differences within and between populations. Significance levels for variance component estimates were calculated by permutational procedures. The number of permutations for significance testing was set at 100 for all analyses. An unweighted pair group mean average (UPGMA) clustering analysis was carried out using a distance matrix based on the Phi statistic (PhiST) produced by the AMOVA analysis for between-population distances.

\section{Results}

\section{Genetic diversity of Banksia and Dryandra}

Band data for the three selected primers were pooled such that each species had total band numbers ranging from 48 to 89 . The number of monomorphic bands was low, with most bands polymorphic (Table 1). Analysis of RAPD data for three Banksia species with each of the six published statistical methods gave a wide range of estimates of genetic diversity (Table 2). The species were chosen on the basis that there were reported estimates of outcrossing rates and genetic diversity based on allozyme electrophoresis data (Scott, 1980; Coates \& Sokolowski, 1992). With high outcrossing rates and animal pollination in these Banksia species high levels of genetic variation are expected within a species, with most variation occurring within rather than between populations. This suggests that the methods of Nei \& Li (1979), Jaccard (1901) and Russell \& Rao (1940) are most appropriate and these were subsequently used for analysis of the total data set.

The estimates of genetic diversity for all species with the three chosen metrics were high, ranging from 0.59 for Banksia praemorsa, B. menziesii and Dryandra formosa, up to 0.90 for B. lemanniana and B. cuneata (Table 1).

\section{Genetic diversity of $\mathrm{B}$. cuneata}

The five primers yielded a total of 169 polymorphic bands (Table 3). No monomorphic bands were scored and the number of markers per primer ranged from 30 (OPA-4) to 37 (OPA-9, OPA-16). Of the 169 RAPD markers scored, 33 (19.5 per cent) were present in all populations and there were no fixed differences between populations, with the remaining 136 (80.5 per cent) bands variable between populations. Most bands occurred at a frequency of 0-20 per cent, with relatively few bands in the $80-100$ per cent category (Table 4). The total number of bands present in each population was similar, with the exception of population 10 with only three individuals, which had only half the number of bands (Table 4).

The total genetic diversity for $B$. cuneata of $D=0.70$, calculated by this study, was high for a rare species (Table 5). The diversity within each population ranged from 0.65 (population 10) to 0.74 (population 2), with greatest genetic diversity estimates in the larger populations $(2,3,4)$ compared to the smaller populations $(7,8,10)$. AMOVA analysis (Table 6) attributed nearly all of the variation to individuals within populations. Analysis between populations showed a small negative variance component, indicating lack of population structure,

Table 2 Genetic diversity of three species of Banksia calculated from RAPD data using six different methods

\begin{tabular}{lcccccc}
\hline & \multicolumn{5}{c}{ RAPD analysis } \\
\cline { 2 - 5 } Species & $\begin{array}{c}\text { Nei \& Li } \\
(1979)\end{array}$ & $\begin{array}{c}\text { Jaccard } \\
(1901)\end{array}$ & $\begin{array}{c}\text { Russell \& Rao } \\
(1940)\end{array}$ & $\begin{array}{c}\text { Apostol } \text { et al. } \\
(1993)\end{array}$ & $\begin{array}{c}\text { Excoffier } \text { et al. } \\
(1992)\end{array}$ & $\begin{array}{c}\text { Rodgers \& Tanimoto } \\
(1960)\end{array}$ \\
\hline B. attenuata & 0.77 & 0.74 & 0.86 & 0.41 & 0.25 & 0.57 \\
B. menziesii & 0.65 & 0.59 & 0.77 & 0.35 & 0.29 & 0.51 \\
B. cuneata & 0.80 & 0.78 & 0.90 & 0.36 & 0.28 & 0.52 \\
\hline
\end{tabular}


with some plants being more related between populations than within. That there was no distinction between populations of $B$. cuneata was reflected by the absence of fixed differences between populations in RAPD markers. UPGMA clustering with low levels of genetic diversity between populations, reflected the lack of genetic differentiation between the 10 populations.

\section{Discussion}

This study shows that by using RAPDs the 33 species of Banksia and the three species of Dryandra tested have high levels of estimated genetic diversity. The levels of expected genetic diversity in $B$. cuneata populations are in agreement with results from enzyme electrophoresis (Coates \& Sokolowski, 1992) which estimated outcrossing rates ranging from $0.67-0.95$, with low levels of selfing. Genetic diversity using RAPDs is high for a geographically restricted rare and endangered species.

Table 3 Summary of data obtained by RAPD analysis for five primers with 125 individuals of Banksia cuneata

\begin{tabular}{llc}
\hline Primer & $\begin{array}{c}\text { Primer sequence } \\
5^{\prime} \text { to } 3^{\prime}\end{array}$ & $\begin{array}{c}\text { Number of } \\
\text { polymorphic bands }\end{array}$ \\
\hline OPA-1 & CAGGCCCTTC & 33 \\
OPA-4 & AATCGGGCTG & 30 \\
OPA-9 & GGGTAACGCC & 37 \\
OPA-11 & CAATCGCCGT & 32 \\
OPA-16 & AGCCAGCGAA & 37 \\
& Total & 169 \\
& Mean per primer & 33.8 \\
\hline
\end{tabular}

The 10 populations of Banksia cuneata show only slight differences in the levels of genetic diversity. Populations 1, 6, 7 and 10 occur in highly disturbed roadside vegetation, populations $3,4,8$ and 9 show low levels of disturbance, whereas populations 2 and 5 have virtually untouched vegetation. Population 10 was a highly disturbed small population of only three individuals, and showed the lowest diversity of 0.65. The larger populations with low levels of disruption had the highest diversity estimates ranging from 0.71 to 0.74 .

The lack of population differentiation in Banksia cuneata using RAPDs contrasts with evidence of population structure using allozymes (Coates \& Sokolowski, 1992). Their study using six populations and six polymorphic loci found significant differentiation of populations into east and west groups, with a salt river system acting as an ecological barrier to pollinator movement. The westerly populations were reported to be heterogeneous, and some populations which were geographically close were more related to distant populations. In the eastern populations, gene flow was reported to be relatively high, suggesting that birds as pollinators (Ayre \& Whelan, 1989) were effective in maintaining genetic cohesion and diversity. Birds are able to travel considerable distances, and associated with areas of $B$. cuneata is a rich and diverse vegetation system for bird foraging and nesting. Since clearing about 50-60 years ago, there has been no significant genetic differentiation between the populations, although population sizes have been reduced. It is possible that after clearing the populations are still visited by pollinators because of surrounding vegetation, which supports the bird population. It is also possible that

Table 4 Summary of band frequencies for 10 populations of Banksia cuneata

\begin{tabular}{|c|c|c|c|c|c|c|c|}
\hline \multirow[b]{2}{*}{ Population } & \multirow{2}{*}{$\begin{array}{c}\text { Number of } \\
\text { samples }\end{array}$} & \multirow{2}{*}{$\begin{array}{l}\text { Number of } \\
\text { bands }\end{array}$} & \multicolumn{5}{|c|}{ Band frequency } \\
\hline & & & $0-20 \%$ & $20-40 \%$ & $40-60 \%$ & $60-80 \%$ & $80-100 \%$ \\
\hline 1 & 10 & 131 & 91 & 28 & 23 & 15 & 12 \\
\hline 2 & 20 & 157 & 93 & 37 & 19 & 13 & 7 \\
\hline 3 & 20 & 161 & 78 & 43 & 24 & 18 & 6 \\
\hline 4 & 20 & 145 & 83 & 47 & 20 & 11 & 8 \\
\hline 5 & 10 & 128 & 90 & 28 & 24 & 16 & 11 \\
\hline 6 & 6 & 115 & 94 & 29 & 11 & 18 & 17 \\
\hline 7 & 10 & 135 & 96 & 24 & 23 & 12 & 14 \\
\hline 8 & 6 & 118 & 90 & 20 & 23 & 14 & 22 \\
\hline 9 & 20 & 145 & 91 & 32 & 23 & 18 & 5 \\
\hline 10 & 3 & 66 & 103 & 34 & 0 & 15 & 17 \\
\hline Mean & & 130.1 & 90.9 & 32.2 & 19.0 & 15.0 & 11.9 \\
\hline
\end{tabular}


the populations are ageing and there have been too few generations since clearing to see any significant genetic differentiation.

The relationships between the six distance metrics tested have been discussed by Gower (1985). Some of the metrics are related by simple monotonic functions and the distances they produce are linearly or curvilinearly related. Thus the metrics of $\mathrm{Nei} \& \mathrm{Li}$ (1979) and Jaccard (1901) form one group, and Rodgers \& Tanimoto (1960), Excoffier et al. (1992) and Apostol et al. (1993) form another, with the metric of Russell \& Rao (1940) producing distances that are poorly related to those produced by any of the others. Our results are consistent with Gower's (1985) expectations, and suggest that the Nei \& Li (1979), Jaccard (1901) or Russell \& Rao (1940) methods are the most appropriate for RAPD data sets. AMOVA is not strictly rigorous with non-Euclidean metrics, but as Excoffier et al. (1992) point out, the metric of Nei \& Li (1979) differs only in the choice of denominator and the metric is nearly interchangeable with the Euclidean metric.

Table 5 Genetic diversity of 10 populations of Banksia cuneata calculated using the similarity $(F)$ metric of Nei \& Li (1979), where distance $D=1-F$

\begin{tabular}{lccc}
\hline Population & $\begin{array}{c}\text { Number of } \\
\text { plants sampled }\end{array}$ & $\begin{array}{c}\text { Mean distance } \\
\text { (diversity) }\end{array}$ & $\begin{array}{c}\text { Standard } \\
\text { deviation }\end{array}$ \\
\hline 1 & 10 & 0.68 & 0.085 \\
2 & 20 & 0.74 & 0.096 \\
3 & 20 & 0.73 & 0.067 \\
4 & 20 & 0.73 & 0.053 \\
5 & 10 & 0.68 & 0.073 \\
6 & 6 & 0.70 & 0.065 \\
7 & 10 & 0.67 & 0.070 \\
8 & 6 & 0.67 & 0.032 \\
9 & 20 & 0.71 & 0.080 \\
10 & 3 & 0.65 & 0.017 \\
Total & 125 & 0.70 & 0.031 \\
\hline
\end{tabular}

The Amova method, designed for other molecular data, has recently been used to analyse RAPD data for buffalo grass (Huff et al., 1993), Eucalyptus (Nesbitt et al., 1995) and Grevillea (Rossetto et al., 1995).

It is important for future conservation and persistence of $B$. cuneata and other rare species that the remaining populations are protected. Even though they have reasonably high levels of diversity, this study shows that genetic diversity may decline in very small populations, such as population 10 with only three individuals. Pollinator maintenance is essential for plant genetic diversity, and reserves which have other coexisting vegetation to support pollinators must also be protected. The distribution of these reserves, to allow gene flow between populations, is important for the survival of $B$. cuneata, as well as maintaining genetic diversity in other plant species.

\section{Acknowledgements}

Thanks to the Department of Conservation and Land Management, Western Australia, for seed material and a permit to collect seed from Banksia cuneata populations, to Leon Silvester for assistance in seed collection, to Dr David Coates for encouragement and discussion, to Dr Rod Peakall for assistance with computer analysis and to Laurent Excoffier for providing WINAMOVA software. T. L. M. is a recipient of an Australian Postgraduate Research Award and the project was funded by the Australian Research Council and an International Protea Association Research Award.

\section{References}

AMSTRONG, J., GIBBS, A., PEAKALL, R. AND WEILLER, G. F. 1994. RAPDISTANCE: random amplified polymorphic DNA analysis. Computer program distributed by the Australian National University. http://life.anu.edu.au/Molecular/Software/rapd.html.

Table 6 Analysis of molecular variance (AMOVA) for 125 individuals in 10 populations of Banksia cuneata using 169 RAPD bands. The data show the degrees of freedom (d.f.), sum of squared deviation (SSD), mean squared deviation (MSD), variance component estimate, percentage of total variance contributed by each component and the probability $(P)$ of obtaining a more extreme component estimate by chance alone

\begin{tabular}{lrrrrrr}
\hline Source of variation & d.f. & SSD & MSD & Variance component & $\%$ total & $P$-value \\
\hline $\begin{array}{l}\text { Analysis among populations } \\
\text { Between populations }\end{array}$ & 9 & 1.446 & 0.161 & -0.0160 & 0.57 \\
Within populations & 115 & 40.821 & 0.355 & 0.3549 & -4.73 & 104.73 \\
\hline
\end{tabular}


ANDERSON, W. R. AND FAIRBANKS, D. J. 1990. Molecular markers: important tools for plant genetic resource characterisation. Diversity, 6, 51-53.

APOSTOL, B. L., BLACK, W. C., IV, MILLER, B. R., REITER, P. AND BEATY, B. J. 1993. Estimation of the number of full sibling families at an oviposition site using RAPD-PCR markers: applications to the mosquito Aedes aegypti. Theor. Appl. Genet., 86, 991-1000.

AYRE, D. J. AND WHELAN, R. J. 1989. Factors controlling fruit set in hermaphroditic plants: studies with the Australian Proteaceae. Trends Ecol. Evol., 4, 267-272.

CARTHEW, S. M., AYRE, D. J. AND Whelan, R. J. 1988. High levels of outcrossing in populations of Banksia spinulosa R.Br. and Banksia paludosa Smith. Aust. J. Bot., 36, 217-223.

CHALMERS, K. J., SPRENT, J. 1., SIMONS, A. J., WAUGH, R. AND POWEll, w. 1992. Patterns of genetic diversity in a tropical tree legume (Gliricidia) revealed by RAPD markers. Heredity, 69, 465-472.

COATES, D. J. AND SOKOLOWSKr, R. E. S. 1992. The mating system and patterns of genetic variation in Banksia cuneata A. S. George (Proteaceae). Heredity, 69, 11-20.

EXCOFFIER, L., SMOUSE, P. E. AND QUATTRO, J. M. 1992. Analysis of molecular variance inferred from metric distances among DNA haplotypes: application to human mitochondrial DNA restriction sites. Genetics, 131, 479-491.

GEorge, A. S. 1981. The genus Banksia L.f. (Proteaceae). Nuytsia, 3, 239-473.

George, A. s. 1987. The Banksia Book. Kangaroo Press, Sydney.

GEORGE, A. s. 1988. New taxa and notes on Banksia L.f. (Proteaceae). Nuytsia, 6, 309-317.

GOWER, J. C. 1985. Measures of similarity, dissimilarity and distance. In: Klotz, S. and Johnson, N. L. (eds) Encyclopedia of Statistical Sciences, vol. 5, pp. 397-405. Wiley, New York.

HUFF, D. R., PEAKAll, R. AND SMOUSE, P. E. 1993. RAPD variation within and among natural populations of outcrossing buffalograss [Buchloë dactyloides (Nutt.) Engelm.]. Theor. Appl. Genet., 86, 927-934.

JACCARD, P. 1901. Etude comparative de la distribution florale dans une portion des Alpes et des Jura. Bull. Soc. Vaudoise Sci. Nat., 37, 547-579.

NEl, M. AND L1, w. H. 1979. Mathematical model for studying genetic variation in terms of restriction endonucleases. Proc. Natl. Acad. Sci. U.S.A., 74, 5267-5273.

NESBITT, K. A., POTTS, B. M., VAILlANCOURT, R. E., WEST, A. K. AND REID, J. B. 1995. Partitioning and distribution of RAPD variation in a forest tree species, Eucalyptus globulus (Myrtaceae). Heredity, 74, 628-637.

RODGERS, D. J. AND TANIMOTO, T. T. 1960. A computer program for classifying plants. Science, 132, 1115-1118.

ROSSETTO, M., WEAVER, P. K. AND DIXON, K. W. 1995. Use of RAPD analysis in devising conservation strategies for the rare and endangered Grevillea scapigera (Proteaceae). Mol. Ecol. , 4, 321-329.

RUSSELL, P. F. AND RAO, T. R. 1940. On habitat and association of species of anopheline larvae in south-eastern Madras. J. Malar. Inst. India, 3, 153-178.

SAMBROOK, J., FRITSCH, E. F. AND MANIATIS, T. 1989. Molecular Cloning: A Laboratory Manual, 2nd edn. Cold Spring Harbor Laboratory Press, Cold Spring Harbor, NY.

SCHEMSKE, D. W. AND LANDE, R. 1985. The evolution of self-fertilization and inbreeding depression in plants. II. Empirical observations. Evolution, 39, 41-52.

scoTt, J. K. 1980. Estimation of the outcrossing rate for Banksia attenuata R.Br. and Banksia menziesii R.Br. (Proteaceae). Aust. J. Bot., 28, 53-59.

VIRK, P. S., FORD-LLOYD, B. V., JACKSON, M. T. AND NEWBURY, H. J. 1995. Use of RAPD for the study of diversity within plant germplasm collections. Heredity, 74, 170-179.

WEINING, s. AND LANGRIDGE, P. 1991. Identification and mapping of polymorphisms in cereals based on the polymerase chain reaction. Theor. Appl. Genet., 82, 209-216. 